\title{
Static Risk Mapping of Forest Fires \\ In the case of the Province of Chefchaouen (Morocco)
}

\author{
Malak Alasli \\ Department of Earth sciences, Eötvös Loránd University, alaslima.ma@ gmail.com
}

\begin{abstract}
:
Forest fire is responsible for a lot of problems as it destroys the landscape. Such spaces are valuable and take very long to recover. Hence, the risk of forest fire consists primarily of both the risk of an outbreak and of propagation which depend, in addition to the weather, to a number of environmental factors including: the type of vegetation (structure and composition), its state of desiccation as well as the slope and exposure to prevailing winds. Therefore, the goal is to develop static hazard maps of a $100 \mathrm{~m}$ resolution related to the province of Chefchaouen where the focus is on three maps; Surface threatened; Annual pressure of fire; Probability map. The production of these maps is based on various data including statistics on the fire, meteorological references, and flammability. In addition, several data were generated, namely, wind direction, wind speed, humidity, the slope in percent, aspect, etc. The production of these maps will make it possible to orient and optimize the means of investment, in particular with regard to infrastructures, equipment and forest fire management operations.
\end{abstract}

Keywords: forest fire, GIS, hazard mapping, risk assessment

\section{Introduction}

Fire is the main natural threat to the forests and woodlands of the Mediterranean basin. It destroys more trees than all other natural disasters combined (pests, insects, tornadoes, frost, etc.). The deforestation factor to fight first was therefore fire. An FAO study (2007) found that globally, 350 million hectares of natural areas are affected by wildfires each year, representing 9 percent of the total area of forests and non-forested areas. such as savannah, bush and rangelands.

Forest fires heavily affect the whole society, the state, and the local authorities in particular. Thus, the country's forest policy should take into account scientific innovations in management and heritage protection. In fact, the complexity and diversity of the environmental data favor the development of systems capable of meeting the needs of the collection, analysis, and representation of environmental phenomena. Geographic Information Systems (GIS) have become an essential tool for the understanding and monitoring of dynamic occurrences and a need for investment and orientation of valid arguments for decision making. Thus, it is important to implement a methodology to develop decision maps to optimize and improve the efficiency of equipment and means of intervention.

\subsection{Literature review}

Thanks to its privileged geographical position, between the Mediterranean in the north, the Atlantic Ocean in the west and the Sahara in the south, and thanks to the importance of the mountain ranges, some of which exceed four thousand meters of altitude, Morocco presents a great bioecological diversity and a very important range of different natural environments.

The kingdom of Morocco is made of 70 percent of mountains and 30 percent of plains. Its forested forest formations cover an area of 5,814,000 ha, made up of 63 percent deciduous species (holm oak [Quercus ilex], cork oak [Quercus suber], argan [Argania spinosa] and Saharan acacias [Acacia spp.]) and 20 percent conifers (cedar [Cedrus spp.], thuya [Tetraclinis articulata], juniper [Juniperus spp.], pine [Pinus spp.], Atlas cypress [Cupressus atlantica], and fir [Abies spp.]). The remaining 17 percent is occupied by low formations (scrub and secondary species) often resulting from forest degradation. Forests are not only a reservoir of carbon dioxide but also an important source of oxygen, a regulator of the flow of the hydrographic system, and a large stock of solar energy. 
Etymologically, the word forest evokes a particularly protected territory intended for hunting or wood production. In colloquialism, this term designates an important area covered with trees. Economically, the forest estate covers 30 percent of the country's timber and industrial needs $(600,000 \mathrm{~m} 3$ of lumber and industry, and 129,500 cubic meters of cork per year). It makes it possible to cover 17 percent of the food needs of the national livestock, equivalent to 15 million quintals of barley/year. Consequently, nearly 10 million small livestock units stay in forest rangelands between 6 and 12 months depending on the regions and types of forest formations. In addition, the forest accounts for 30 percent of the overall energy balance at the national level (AEFCS, 1996). Besides, the Moroccan forest produces a multitude of goods and services (handicrafts, honey, truffles, fruits, mushrooms, acorns, hunting, fishing, etc.). In this category, aromatic and medicinal plants (rosemary, sagebrush, Bay laurel (Laurus nobilis), thymes, etc.) are an important component. In the environmental field, the forest contributes to the protection of the soil against wind erosion resulting in the displacement of the coastal and continental dunes that threaten towns, oases, palm groves, communication routes etc. It also helps in the fight against water erosion in much of the country, and desertification.

\subsubsection{The Moroccan forest estate}

The main forest regions of Morocco are:

- The Rif with an afforestation rate of $15 \%$

- The Middle Atlas with a rate of afforestation of $25 \%$

- The Atlantic Cork Oak region Rabat - Oulmes 25\%

- The High Atlas at afforestation rate of $28 \%$

- The region of Souss and argan with a rate of $23 \%$

These five regions account for $3 / 4$ of the country's forestlands, and their afforestation rate is at a remarkable level. In spite of the heterogeneity of the Moroccan forest, one can indicate the following distributions in the essences; deciduous occupy more than $1 / 2$, and coniferous forest just under a third of the total forest area.

The first National Forest Inventory (NFI), carried out between 1990-2005, made it possible to have a reliable and significant cartographic and digital database on the geographical distribution, the consistency, and the overall state of the forest resources.

\subsection{Forest fire}

Forest fires are a chronic and recurrent phenomenon (Velez, 1999), whose intensity is still increasing. This phenomenon concerns the majority of the countries, and more particularly those of the Mediterranean basin where the fire is the main reason for the disappearance of its forests. About 50,000 fires ravage each year an area of 700,000 ha to 1 million ha of Mediterranean forest.

The severity of forest fires varies by region. It is directly related to the type of vegetation and particularly the undergrowth. The Rif region of Morocco is more sensitive than others and the most affected; it loses about 1,185 ha/year, or 43 percent of the total area burned at the national level.

From the analysis of the forest fire review between the 1960s and 2004, there is an average of 230 fires per year for an average annual area affected of 2800 ha, with maxima in the order of 11000 ha in 1983 and 8600 ha in 2004. Although there is a large year-to-year fluctuation, due to climate change and mainly desiccation, over the past decade there has been a trend of increasing the number of fires and the areas affected, particularly in the north of the country (Rif). This variation is due, on the one hand, to the high fire sensitivity of local forests, and on the other hand, to the strong pressure exerted on the forest estate and the use of fire as a practice of cleaning up woodlands for their cultivation.

The analysis of the forest fire situation in Morocco shows that during 50 years (1960-2009), nearly 12,912 fires damaged 149,292 ha of forests, an average of 2,986 ha per year, with a total of maximum in 1983 (11,289 ha) and a minimum in 2002 (593 ha). This average annual area represents 0.05 percent of the total forested area of the country. According to official statistics, during the ten years of 2001 to 2011, an average area of 4.5 ha per year has been invaded by fires, with a very high rate in 2010 (343.33 ha) and a minimum in 2003 (0.08ha). This unveils that an extensive part of the national ecological heritage is at risk.

A forest fire is a complex process with several factors at play, including those related to the environment (relief, climate, flora), and those related to humans. These different parameters are strongly interrelated and have a prominent influence on the probability of outbreak and magnitude of the fire. There are different sources of ignition (VELEZ, 1999, DIMITRAKOPOULOS \& MITSOPOULOS, 2006).

\subsubsection{Firepower}

After the appearance of flames, the fire spreads slowly for a few minutes or a few tens of minutes; then it reaches a relatively stable regime according to the nature and the distribution of the vegetable fuel, the state of the atmosphere, the temperature, and the wind.

In the first few minutes, the firepower remains very low and is easy to control and extinguish. As soon as the fire reaches a stable regime, its control depends on its power $P$ (expressed in $\mathrm{kW}$ per meter of front), in relation to its 
speed of propagation, $\mathrm{R}$ (in meters per second), and of the quantity of biomass burned, w (in $\mathrm{kg}$ per square meter): $\mathrm{P}$ $=18,700 \mathrm{R} \mathrm{w}$ (Alexander, 1982, Valette, 1988).

For a forest fire to start, three factors are needed: fuel (vegetation), an oxidizing gas (oxygen from the air), and a source of ignition (a flame or incandescent material). The water content plays an essential role since the fuel ignites only after having lost a large quantity of its water by evaporation. Thus, living plants are more flammable and not very combustible, unlike dead plants that are very poor in water.

\subsubsection{Characteristic of the fuel}

The water content of the plants constituting the fuel is the most prominent factor altering the behavior of fire. It determines the probability of ignition, the speed of propagation, and the amount of fuel burned. Mediterranean vegetation which is rich in the resin (softwood forests) and low moisture content burns easily (SCHNITZLER-LENOBLE, 2002). Dry fuel ignites more easily than waterlogged fuel.

\subsection{3 weather conditions}

Weather factors that influence the behavior of fires include temperature, wind, and precipitation. Temperature can have a direct influence by heating or cooling materials, or indirectly by changing the moisture content of the atmosphere.

\subsubsection{Topographical factors}

Topography is a constant variable, that is, it does not change over time. We can easily ascertain its influence. Two main topographic parameters affect fire. The slope by amplifying the effect of radiation and convection, and the exposure by varying the amount of heat received as a function of insolation and the density and structure of the vegetation. Moreover, the slope and the exposure strongly influence the climate.

In general, the southern and southwestern slopes have the most favorable conditions for rapid ignition and fire spread, as they receive more direct sunlight and therefore air and fuel temperatures are higher than on the other slopes (TRABAUD, 1991, QUEZEL \& MEDAIL, 2003).

\section{Methodology}

\subsection{Area of study}

Chefchaouen is a city in the Rif Mountains of northwest Morocco.

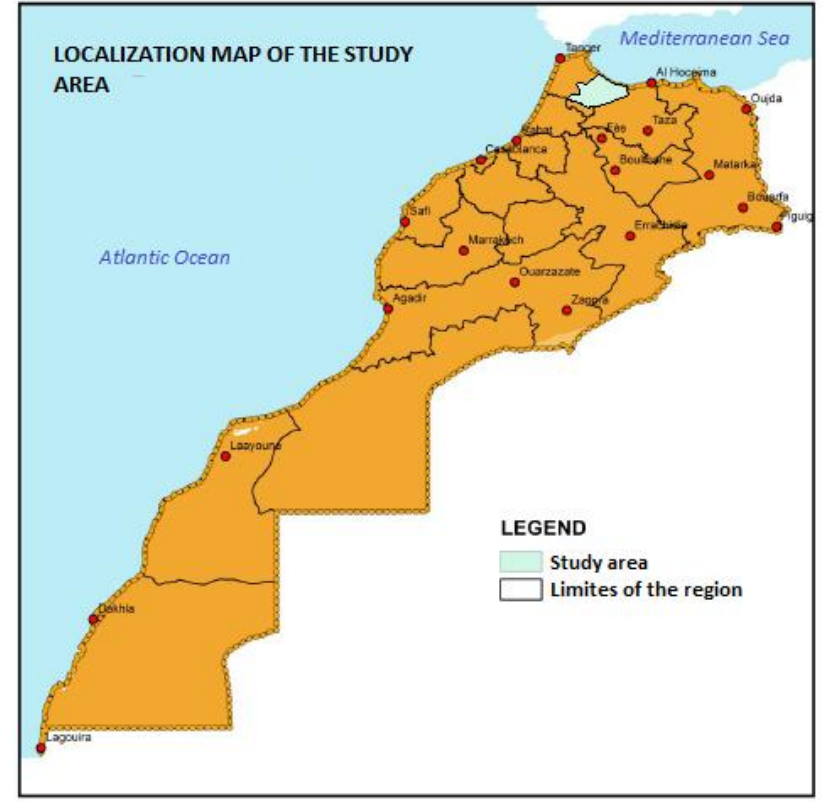

Figure 1. Location of the study area

\subsection{Data collection}

The data collected comes from the Forest Protection Service of the Directorate for Combating Desertification and Nature Protection. These data are:

- National Forest Inventory (NFI);

- Flammability;

- The number of fires in Chefchoauen for a period of 17 years;

- The burned surfaces in the province of Chefchaouen for a period of 17 years;

- One-time weather data relating to wind direction and humidity;

- Municipalities (Figure 2).

In addition to these data, the Digital Elevation Model (Figure 3) was downloaded from the Internet from ASTER images at a resolution of $30 \mathrm{~m}$.

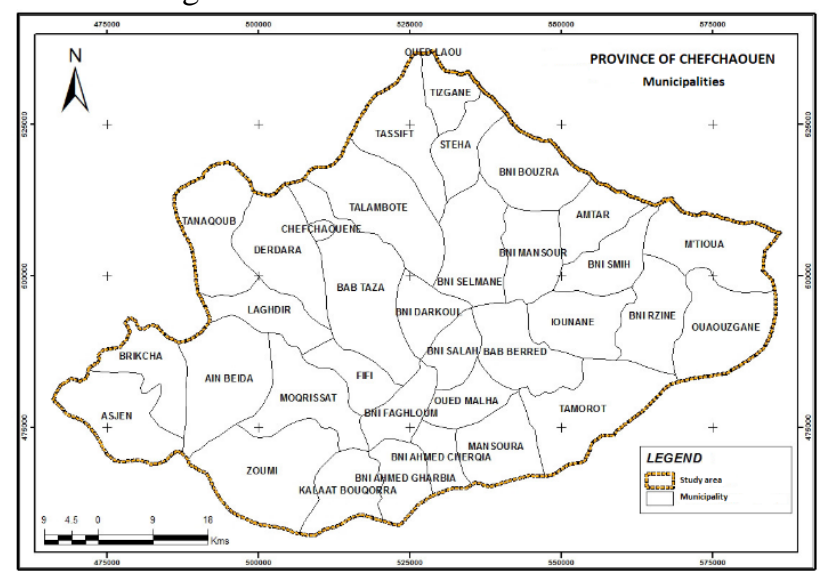

Figure 2. The municipalities 


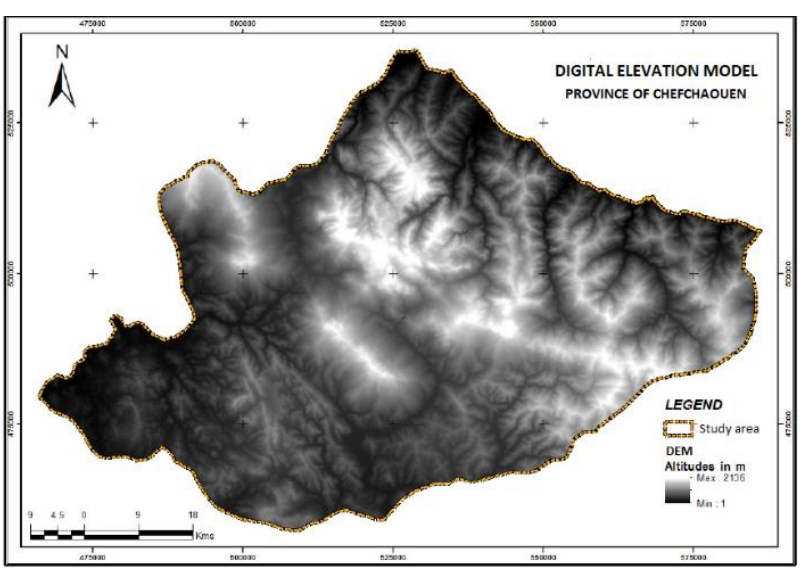

Figure 3. Digital elevation Model

\subsection{Procedures and modelling}

For the outbreak of a fire and its spread, the presence of the three factors below are necessary:

- Triggering requires a flame to be a source of heat (flame, spark),

- a supply of oxygen (activated by the wind or the slope of the grounds),

- fuel (vegetation, tree species, etc.).

These three factors define what is called the fire triangle (Figure 4). Moreover, this figure clearly identifies the type of data to be collected, and the parameters to be included in the modeling. Indeed, we can see that there are three categories of data to collect:

- Fire history: sites, areas, date, time, source of fire, etc.

- Physical data: topography of the terrain (slopes, and wind (speed, direction,

- etc.)

- Fuel data: National Forest Inventory (NFI) updated and studied to derive biomass and flammability data.

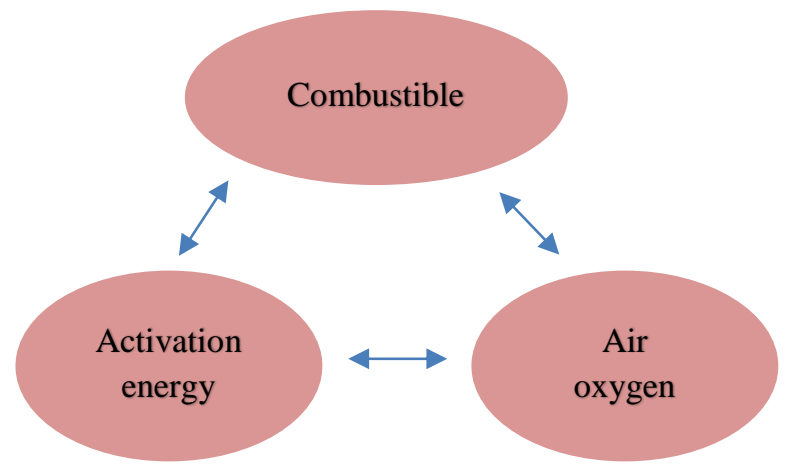

Figure 4. The fire triangle

The figure below illustrates the flowchart of the different steps of the general methodology followed

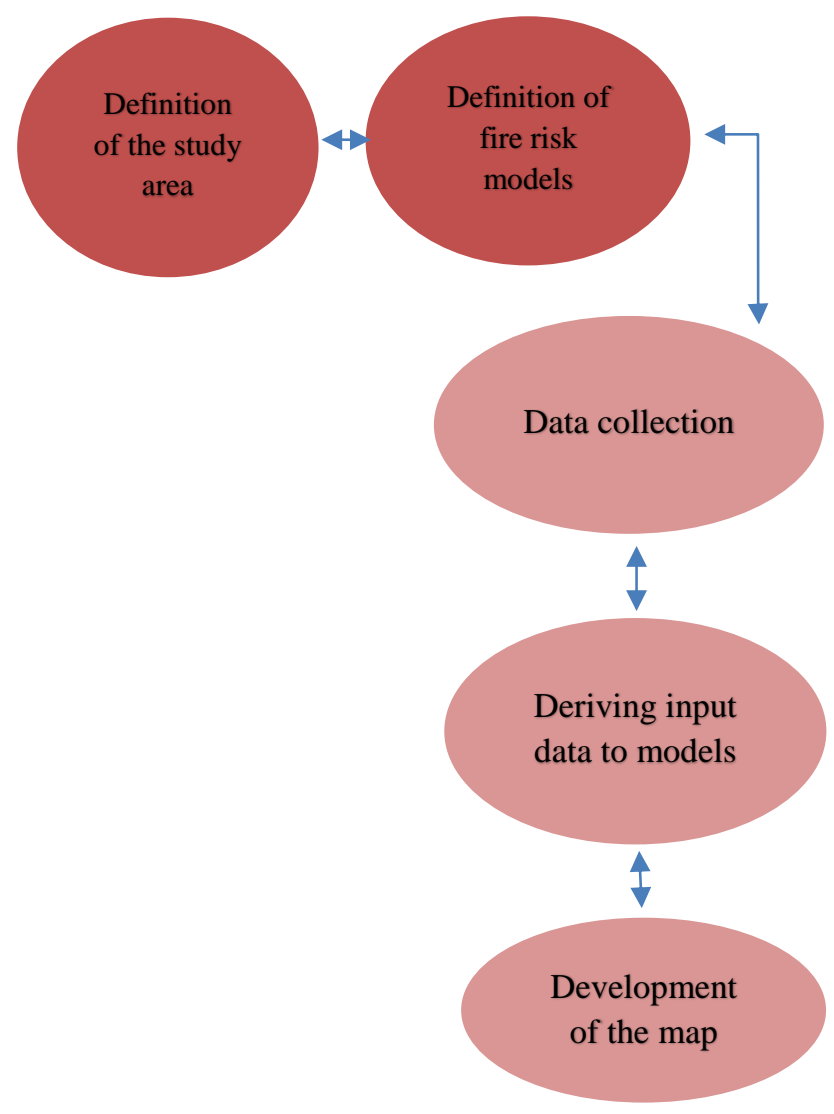

Figure 5. General organization chart of the steps of the methodology

The models to be used depend on the target maps. Thus, we will present each map and the appropriate paradigm to use. It is also worth noting that the period used for the fire history study is 17 years from 1997 to 2013.

\subsubsection{Static Map of Threatened Surface}

This type of map does not need a model and merely requires aggregating all NFI units to form continuous surfaces.

This map is useful for the prevention, the allocation of means of the fight, and the setting up of fuel cuts. Indeed, the decision maker will be in possession of a map that shows them the priority places for incipient fires.

\subsubsection{Static chart of the annual firing pressure}

This map describes the relationship between the number of fires in a municipality and the wooded area of the municipality. Similarly, the model to use is as follows:

- Calculate the number of fires during the chosen 17year period (1997-2013)

- Calculate the area of fuel within each municipality,

- Calculate the ratio between the two. 
The formula is as follows:

$$
\text { AFP }=\text { Total number of fires per municipality }
$$

In this study, the map developed will give the annual firing pressure per $100 \mathrm{~km}^{2}$ of woodland according to the following formula:

$\mathrm{AFP}=10000 \times$ number of fires / wooded area $/ 17$

It is worth mentioning that if the number of fires is zero and the forest area is nonzero, the AFP has been taken as equal to the minimum AFP.

\subsubsection{Static map of the probability of ignition}

It is a critical component of the hazard. Indeed, this map informs the decision-maker about the most probable areas of fire starting, and consequently the places of reinforcement of the surveillance.

This map was developed using the following model:

Probability $=$ Topo climate $\mathrm{x}$ Flammability $\mathrm{x}$ AFP

With

Topo climate $=2.0+\operatorname{Cos}(($ exposure.img - wind.img $) *$ $3.14 / 180.0)+\operatorname{Cos}(($ exposure.img - 180.0) $* 3.14 / 180.0)$

It is worth mentioning that if the terrain is flat (exposure $=$ -1 ) or slope is $<5 \%$, the topo climate is price equal to 2.0

\subsection{The software}

The software used in this study is ArcGIS which remains a complete tool and satisfies the needs of this study.

\subsection{Choice of GIS}

The most appropriate and fastest GIS in terms of data processing is the RASTER mode. Similarly, the same resolution of $100 \mathrm{~m}$ was used.

\subsection{Derivation of intermediate data}

It is worth mentioning that the ArcGIS Data Conversion module and the Spatial Analyst module were used to produce the various data that will be used as input to the previously defined models. Thus, flammability was produced by rasterization of the collected data in vector format. Similarly, the DEM was used to generate percent slopes and exposures (Figure 6). In addition, moisture and wind direction were derived by interpolation and using the weighted inverse distance (IDW) method.

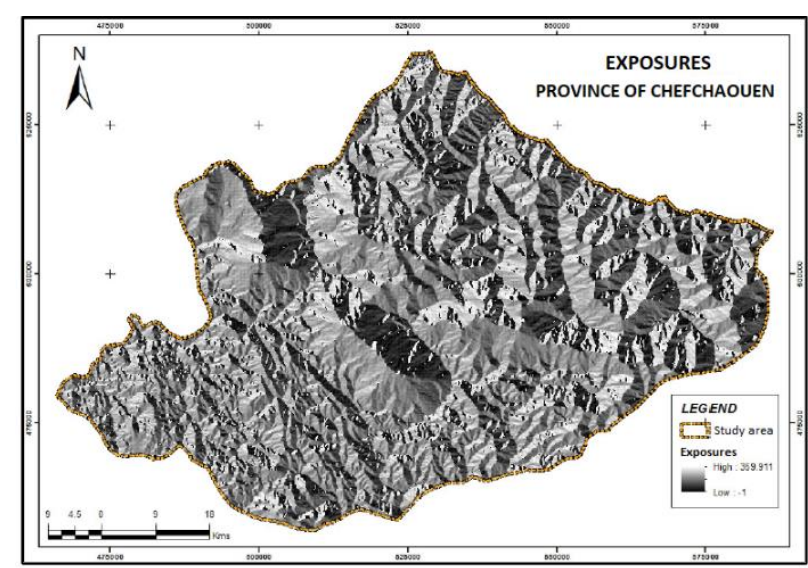

Figure 6. Exposures

\section{Results}

\subsection{Limits of classes used}

It is relevant to first determine the class boundaries used for the development of static maps of forests. These limits are those applied throughout the national territory $(1,2$ and $3)$.

\begin{tabular}{|l|l|}
\hline \multicolumn{2}{|c|}{ Threatened surface (ha) } \\
\hline Class & Limits \\
\hline Very low & $<=100$ \\
Low & $100-200$ \\
Average & $200-300$ \\
High & $300-400$ \\
Very high & $>400$ \\
\hline
\end{tabular}

\begin{tabular}{|l|l|}
\hline \multicolumn{2}{|c|}{ Annual firing pressure } \\
\hline Class & Limits \\
\hline Very low & $<=5$ \\
Low & $5-10$ \\
Average & $10-15$ \\
High & $15-20$ \\
Very high & $>20$ \\
\hline
\end{tabular}

\begin{tabular}{|l|l|}
\hline \multicolumn{2}{|c|}{ Probability of outbreak } \\
\hline Class & Limits \\
\hline Very low & $<=1$ \\
Low & $1-2$ \\
Average & $2-4$ \\
High & $4-6$ \\
Very high & $>6$ \\
\hline
\end{tabular}

\subsection{Establishing static maps of risk}

Figures 7,8 and 9 respectively illustrate the threatened surface maps, the annual firing pressure, and the probability of outbreak. 


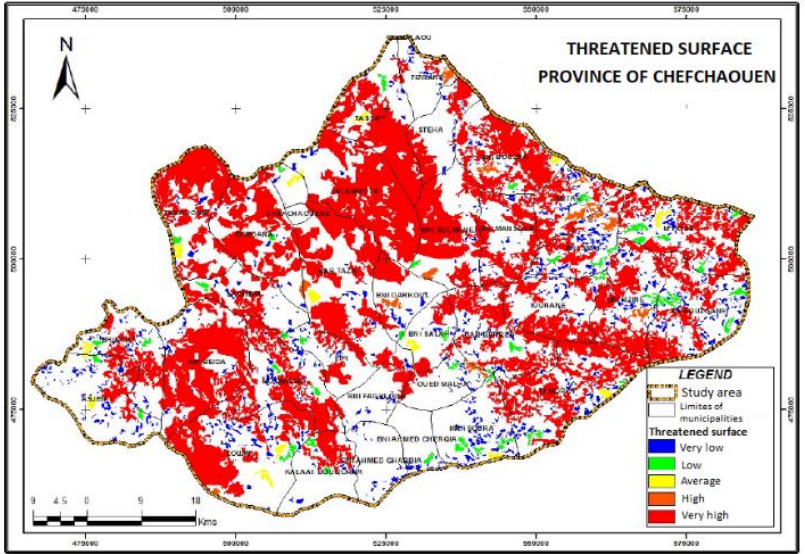

Figure 7. Static Map of Threatened Surface

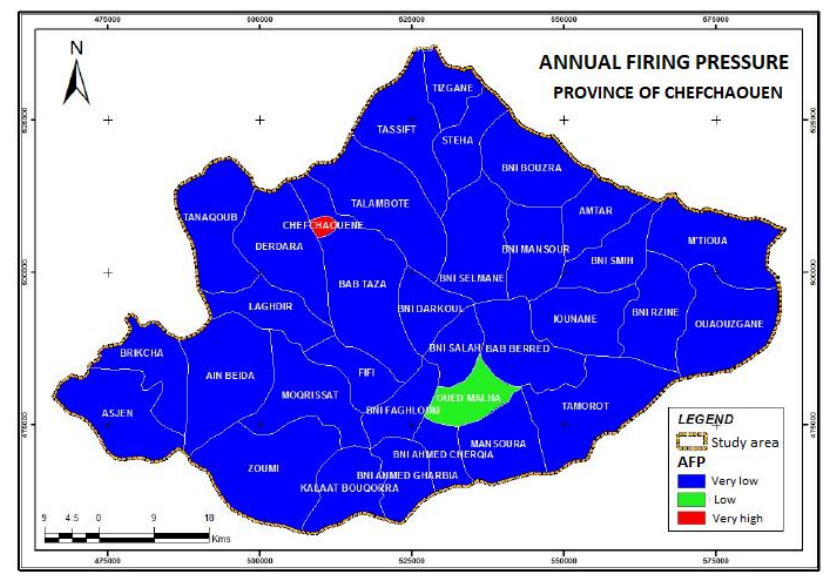

Figure 8. Static chart of the annual firing pressure

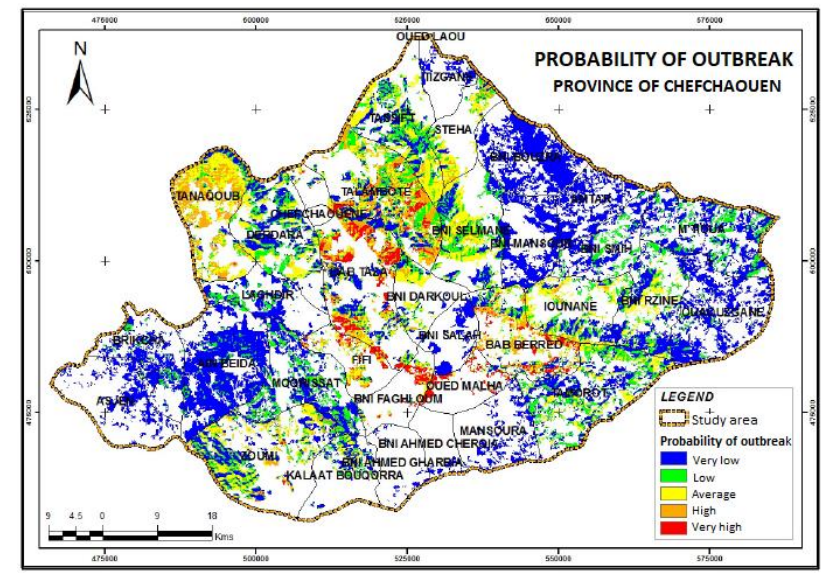

Figure 9. Static map of the probability of ignition

\section{Conclusion and recommendations}

The purpose of this work was to develop risk thematic maps: Threatened surface, annual firing pressure, and the probability of hatching. Statistical data on fires, meteorological data, and flammability data were provided by the Forest Protection Service and were used to derive the corresponding maps to be inserted into static hazard map models. In addition, several data were produced and served as input to fire risk models namely, wind direction, humidity, percentage slope, and exposures.
By developing these three maps, the objectives assigned to this work are achieved. In spite of the very conclusive results, it is useful to recommend the addition of static risk maps for forest fires by the preparation of the annual average risk, and fire intensity maps. In addition, for the ease of execution of different models and to be able to apply them to other regions, it is useful to use the Builder Model of ArcGIS.

\section{References}

AEFCS, 1996 : Actes du colloque national sur la forêt, du 21 au 23 mars 1996 à Ifrane. AEFCS, Rabat. 120 p.

ALEXANDRIAN D., 1995, Intervention anti-incendie nécessaires sur la section courante des autoroutes, Options Méditerranéennes, Série. Al n025, p 121 - 131.

ALEXANDER M.E., 1982, Calculating and interpreting forest fire intensites, Canadian Journal of Botany, vol. 60, pp. 349-357.

BENABID A., 1989 : Ecologie, conservation et restauration des subéraies. Formation continue à l'ENFI.

BENABID A., 1985, Les écosystems forestiers préforestiers et presteppiques du Maroc : Diversité, réparation biogéographique et problèmes posés par leur aménagement. Forêt méditerranéenne, t VII, $n^{\circ} 1$.

CHEVROU Robert, 1998, Prévention et lutte contre les grands incendies de forêts. T. xix $n^{\circ} 2$.

DIMITRAKOPOULOS A.P. \& MITSOPOULOS I.D., 2006. - Report of fires in the mediterranean region. Fire Management Working Papers, Global Forest Ressources Assessement 2005, FM/8/E FAO, Rome, Italie, 43 p.

Direction des Eaux et Forêts du Maroc. Les Forêts du Maroc. In: Revue de botanique appliquée et d'agriculture coloniale, $7^{\mathrm{e}}$ année, bulletin $\mathrm{n}^{\circ} 73$, septembre 1927. pp. 588-592;

EMBERGER L., (1964). - La position phytogéographique du Maroc dans l'ensemble méditerranéen. Al Awamia no $12: 1-15.37$

FAO, 2007 - Situation des forêts du monde (synthèse mondiale). Partie 1 : progrès vers la gestion durable des forêts. pp. 4-13 \& 64-72. www.fao.org

QUEZEL P.\& MEDAIL F., 2003. - Ecologie et biogeographie des forêts du basin méditerranéen. Edition Elsevier, Paris, 571 p.

RAMADE F., 1997. - Conservation des écosystèmes méditéranéens ; enjeux et perspective. Les fascicules du plan bleu n ${ }^{\circ}$. Edition Economica, Paris, 189 p.

SCHNITZLER-LENOBLE A., 2002. - Ecologie des forêts naturelles d'Europe : biodiversité, sylvigénèse, valeur patrimoiniale des forêts primaires. Ed. Tec \& Doc, London, $271 \mathrm{p}$.

VALETTE J-C, 1988, Notions générales relatives à la combustion. Forêt Méditerranéenne, X-1, p 1 97-20 1 .

VELEZ R., 1999 - Protection contre les incendies de forêt : principes et méthodes d'action. CIHEAM, Zaragoza. Options Méditerranéennes, Série B : Études et Recherches No. 26, 118 p. 
TRABAUD L., 1991. - le feu est-il un facteur de changement pour les systèmes écologiques du bassin méditerranéen ? Sécheresse, 3 (2) : 163 - 174.

Website: HCEFLCD, 2004:

www.eauxetforets.gov.ma 